\title{
Successful Treatment of Psoriasis-like Lesions in HIV Infected Patients in Uganda with Chloroquine
}

\author{
Hasan M. Shihab ${ }^{1,4}$, Jordan J. Feld ${ }^{1,5}$, Fred Lutwama ${ }^{1}$, Theresa Piloya ${ }^{1}$ and Robert Colebunders ${ }^{*}, 1,2,3$ \\ ${ }^{I}$ Infectious Diseases Institute, Faculty of Medicine, Makerere University, Kampala, Uganda \\ ${ }^{2}$ Institute of Tropical Medicine, Antwerp, Belgium \\ ${ }^{3}$ University of Antwerp, Antwerp, Belgium \\ ${ }^{4}$ Division of General Internal Medicine, Johns Hopkins University School of Medicine, Baltimore, Maryland, USA \\ ${ }^{5}$ Department of Medicine, University Health Network, Toronto Western Hospital, University of Toronto, Toronto, \\ Canada
}

\begin{abstract}
The effect of chloroquine in the treatment of psoriasis remains controversial. Treatment of psoriasis in HIV infection is not well described. Chloroquine has been shown to have direct effects on both the Human Immunodeficiency Virus (HIV) and on the psoriasis disease process. The effect of chloroquine in HIV infected patients with psoriasis has not been well studied.

We report on the effect of chloroquine on psoriasis-like lesions in three HIV infected patients who were not on antiretroviral therapy. Three consecutive HIV positive patients with CD4 cell count below 200cells $/ \mathrm{mm}^{3}$ had unequivocal improvement of their psoriasis-like lesions after 2 weeks of a daily dose of $150 \mathrm{mg}$ of chloroquine.

In conclusion, chloroquine may be useful in the treatment of psoriasis-like lesions in patients with HIV infection particularly in resource poor settings. Ideally, a controlled clinical trial will be needed to confirm this.
\end{abstract}

Keywords: Psoriasis, Chloroquine, HIV.

\section{INTRODUCTION}

Psoriasis is a common chronic inflammatory skin disease with a world-wide distribution affecting up to $3 \%$ of the world's population [1]. A recent report summarized the prevalence estimates of psoriasis world-wide ranging from $0.6 \%$ to $4.8 \%$ [2]. From a population based study in the United States that involved patient self report of a physician diagnosis of psoriasis, the prevalence was $2.5 \%$ in Caucasians and $1.3 \%$ in African Americans [3]. More recently, a cross sectional study using the National Health and Nutrition Examination Survey 2003-2004 that involved both patient self report of psoriasis and independent review of standardized clinical photographs by two dermatologists determined the prevalence of diagnosed psoriasis to be $3.15 \%$ [2]. Population-based studies from Africa are lacking, however psoriasis was observed to represent less than $1 \%$ of all skin diseases in West African countries such as Nigeria, Mali and Senegal and up to $3.2 \%$ reported in certain studies done in East Africa [4]. In Human Immunodeficiency Virus (HIV) disease, the prevalence of psoriasis is about the same as in the general population at about $1-2 \%[5,6]$. A study from Zambia showed a $3.9 \%$ prevalence of psoriasis among clinic patients, all but one of whom were HIV positive [7].

*Address correspondence to this author at the Institute of Tropical Medicine and University of Antwerp, Nationalestraat 155, B-2000, Antwerp, Belgium; Tel: + 3232476426;

Fax: 3232476432; E-mail: bcoleb@itg.be
HIV infection has however, long been recognized to worsen the course of both psoriasis and psoriatic arthritis [5, 8-13]. Improvement of psoriasis in the setting of HIV infection has been reported with effective antiretroviral therapy $[14,15]$ however, specific treatment remains elusive. Psoriasis treatment with or without concurrent HIV infection is not curative but only suppressive. Antimalarial drugs are generally considered to be contraindicated in psoriasis [16] but, there still is no strong evidence to refute or support the role of antimalarials in the exacerbation of psoriasis [17].

We report three consecutive HIV positive patients with extensive psoriasis-like lesions (Table 1) who were successfully treated with a once daily dose of $150 \mathrm{mg}$ of chloroquine phosphate at the Infectious Diseases Institute Clinic, Mulago Hospital in Kampala, Uganda.

\section{Patient 1 (Fig. 1, Parts $A$ and B)}

A 35-year-old woman presented with a history of a recurrent itchy skin rash for 5 years with little improvement on topical steroid ointments, coal tar and antihistamines. On examination, she had severely hyperkeratotic and pitting nails (onycholysis) and silvery, scaly skin lesions discoid in shape ('leopard skin') all over her trunk, lower limbs and face. She did not have any joint swellings or dactylitis. Her skin condition led her to suspect HIV infection and she had her index HIV test at the clinic. The CD4 count at presentation was $104 \mathrm{cells} / \mathrm{mm}^{3}$. In view of the clinical presentation of the skin lesions, a presumptive diagnosis of psoriasis was made. Topical steroids, tar and antihistamine 
therapy were tried again but had no effect. Highly Active Antiretroviral Therapy (HAART) was not provided free of cost by the Hospital at the time and she was not able to afford it on her own. A decision was made to prescribe daily chloroquine in order to relieve her. A marked improvement was noted after 2 weeks of the daily chloroquine therapy alone. When HAART was available free of cost, she was started on Zidovudine, Stavudine and Nevirapine. The daily chloroquine therapy was gradually weaned off and she did not have a recurrence of the psoriatic rash. She was continued on HAART and her current CD4 count is 463 cells $/ \mathrm{mm}^{3}$.

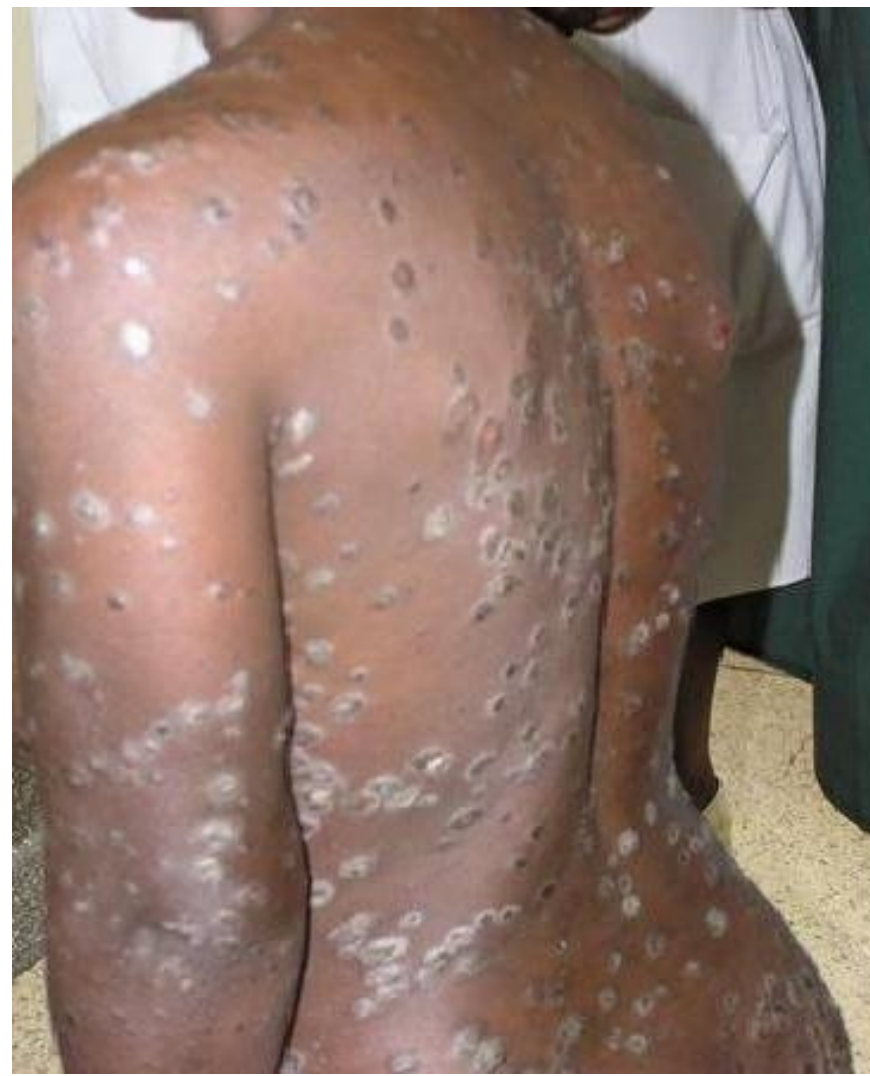

Fig. (1). Part A: 35 year old female with psoriatic- like lesions before chloroquine treatment.

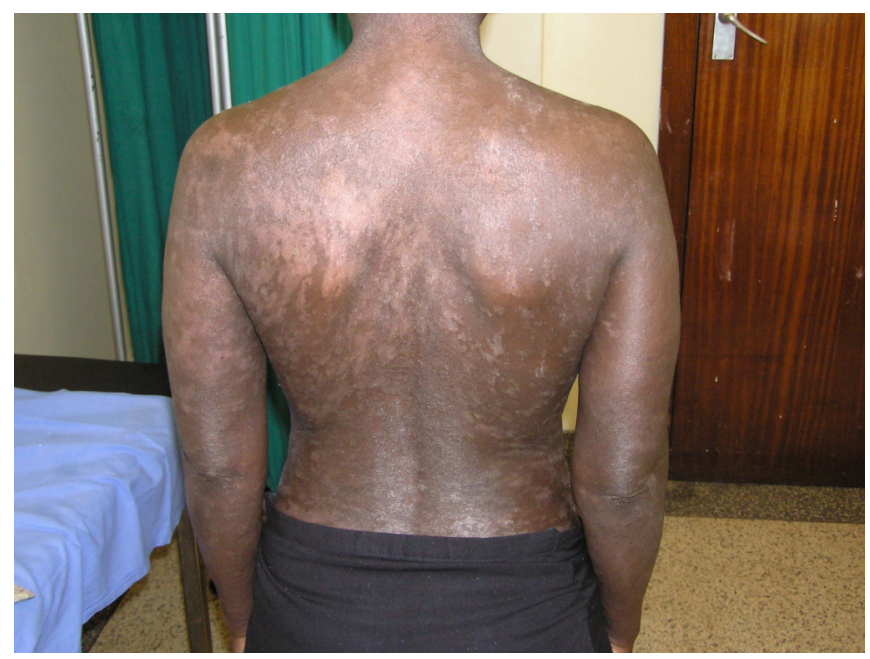

Fig. (1). Part B: 35 year old female after 2 weeks of chloroquine treatment.

\section{Patient 2 (Fig. 2, Parts A and B)}

A 56-year-old man presented with a 2 month history of itchy hypopigmented lesions on the trunk and upper limbs more marked on the extensor surfaces. His CD4 count at initial presentation to the clinic was 47 cells $/ \mathrm{mm}^{3}$. He had previously been treated with topical and oral antifungal drugs, but the rash persisted. A once daily dose of chloroquine was then introduced. Improvement was noted within 2 weeks of therapy. When HAART was offered free to the patients, he was also started on Zidovudine, Stavudine and Nevirapine. The daily chloroquine therapy was gradually weaned off. He did not have a recurrence of the psoriaticlike- rash thereafter.

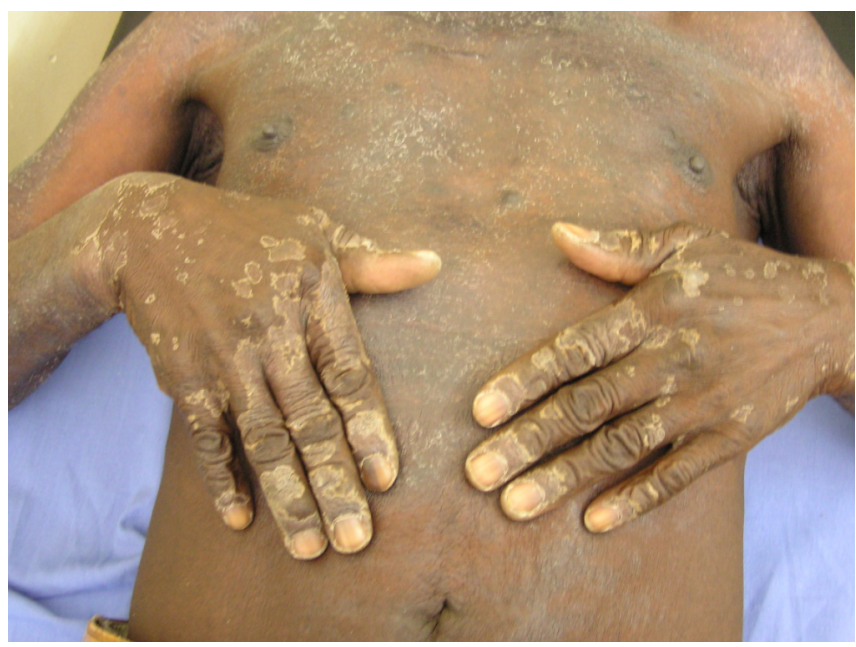

Fig. (2). Part A: 56 year old male with psoriatic- like lesions before chloroquine treatment.

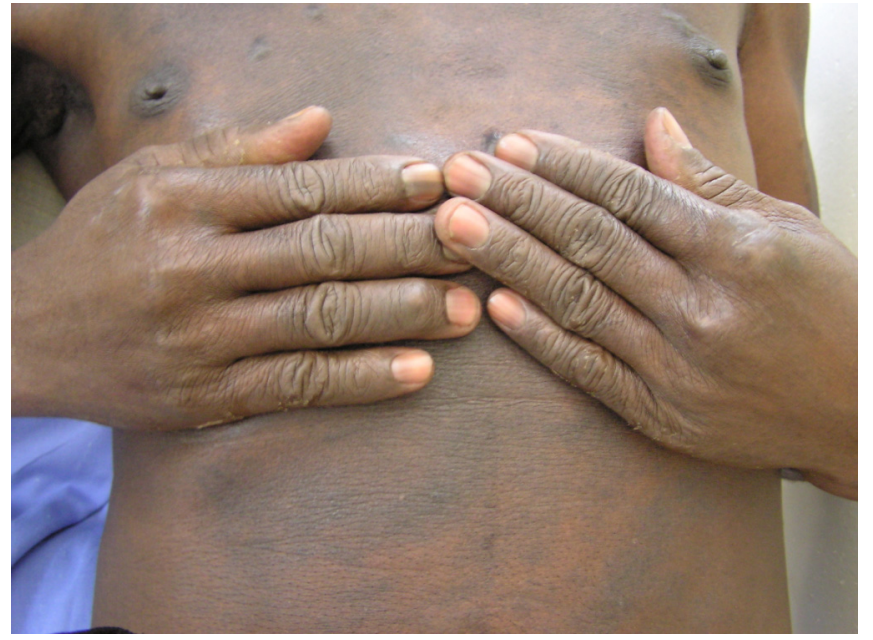

Fig. (2). Part B: 56 year old male after 2 weeks of chloroquine treatment.

\section{Patient 3}

A 33-year-old woman presented with a month history of a generalized pruritic and desquamating rash. She also had multiple painful joint swellings. Her CD4 count at initial presentation to the clinic was 176 cells $/ \mathrm{mm}^{3}$. She was started on Non-Steroidal Anti-inflammatory Drugs and topical hydrocortisone therapy, but there was no improvement. Three months later, she developed onycholysis, the desquamating rash started weeping and became more 
Table 1. Patient Characteristics

\begin{tabular}{|l|c|c|c|l|c|}
\hline Patient & Age (Years) & Sex & CD4 Count $\left(\right.$ Cells $\left./ \mathbf{m m}^{3}\right) \#$ & \multicolumn{1}{|c|}{ Symptoms and Signs } & Treatment Period* \\
\hline \hline Patient 1 & 35 & Female & 104 & $\begin{array}{l}\text { Recurrent itchy rash for 5 years. } \\
\text { Discoid silvery scaly skin lesions. } \\
\text { Severely hyperkeratotic and pitting nails. }\end{array}$ & 2 weeks \\
\hline Patient 2 & 56 & Male & 47 & $\begin{array}{l}\text { Itchy hypopigmented lesions for 2 months. } \\
\text { Non scaly lesions more marked on the extensor surfaces. }\end{array}$ & 2 weeks \\
\hline Patient 3 & 33 & Female & 176 & $\begin{array}{l}\text { Generalized pruritic desquamating rash. } \\
\text { Associated with multiple painful joint swellings. }\end{array}$ & 3 weeks \\
\hline
\end{tabular}

\#- CD4 count at first encounter with patient before treatment was started.

*-Treatment period with chloroquine before symptomatic relief was noted.

extensively distributed on her body. A presumptive diagnosis of psoriasis with psoriatic arthritis was made. She was started on daily chloroquine and marked clinical improvement was noted within 3 weeks of therapy. We were unable to follow this patient through as she stopped attending the clinic when the rash and the joint swellings subsided.

\section{DISCUSSION}

We report three HIV positive patients whose psoriasislike lesions disappeared with chloroquine treatment. A similar effect of antimalarial treatment on psoriasis and psoriatic arthritis has been observed by others [18-22] but exacerbations of psoriasis during antimalarial treatment have also been described [23-27]. These contradictory effects of antimalarials in the treatment of psoriasis were first reported in the literature about chloroquine in 1966 [28]. Four decades later, the data about the benefit of chloroquine and other antimalarials on psoriasis are still inconclusive [17].

Chloroquine and hydroxychloroquine are both 4aminoquinolones and have been used since the 1940s as antimalarials and since the early 1950s in the treatment of rheumatoid arthritis, systemic lupus erythematosus and other autoimmune diseases. In addition, both hydroxychloroquine and chloroquine have been shown to have anti-HIV effects in vitro and in vivo, although chloroquine has been studied more extensively. The inhibition of HIV replication by hydroxychloroquine has been observed in lymphocytes and monocytes from peripheral blood [29]. Although different mechanisms have been proposed for the anti-HIV effect of chloroquine when used alone [30-32] or in combination with protease inhibitors [33], they all suggest a direct inhibitory effect on viral replication. One preliminary study from Uganda has also shown a potential effect of chloroquine in decreasing the rate of HIV vertical transmission [34]. Chloroquine or hydroxychloroquine in combination with anti-retroviral drugs have been shown to reduce the HIV viral load in HIV-1 infected patients [35-38].

The suggestion that antimalarials may be inadvisable in the management of psoriasis [16] is supported by in vitro studies of hydroxychloroquine and chloroquine.

Hydroxychloroquine may induce hyperproliferation, enhancement and irregular keratinization which cause an initial break in the barrier function of the epidermis [39]. Chloroquine has also been shown to abnormally stimulate the lower lymphocyte transformation in controlled experiments in patients with and without psoriasis [40]. The molecular mechanism that has been suggested for the role of chloroquine in the psoriasis disease process is blocking of epidermal transglutaminase, an enzyme that is pivotally involved in the terminal differentiation of keratinocytes [41]. Despite these in vitro experiments showing the potential deleterious effect of chloroquine in psoriasis, the patients we report all improved unequivocally. It is difficult to ascertain whether this improvement seen was caused by the anti-HIV effect of chloroquine or a direct effect of the drug on the psoriasis disease process.

Patient 1 and Patient 3 had the classical clinical features of psoriasis. Given their age and female gender, systemic lupus erythematosus would be another diagnostic consideration. A case report from Iran reported improvement of skin lesions in clinically ascertained discoid lupus erythematosus with chloroquine [42]. Anti-nuclear antibody (ANA) serological tests were not done in our patients. The lesions of Patient 2 were also suggestive of a generalized fungal skin infection but they did not respond to antifungal therapy. Chloroquine has also been shown to be effective in the treatment of fungal infections caused by Histoplasma capsulatum [43], Paracoccidiodes brasiliensis [44] and Cryptococcus neoformans [45]. This effect is thought to be mediated by reducing the availability of iron for the intracellular pathogen [43, 46, 47]. Enhancement of the activity of mononuclear phagocytes by an iron independent $\mathrm{pH}$-dependent mechanism has also been reported [45]. These actions of chloroquine are attributed to the fact that it is a weak base which raises the endocytic and lysosomal $\mathrm{pH}$ of eukaryotic cells [48].

A major limitation of our report is that we could not confirm that our patients had psoriasis. Skin biopsies or skin scrapings to rule out other dermatological conditions such as a fungal dermal infection were not done. The diagnosis of psoriasis has been described as one that can reasonably be made on clinical grounds, although histological examination of a skin biopsy specimen may be helpful [1]. For the diagnosis of psoriasis, no specific test, besides clinical examination has proven useful [49]. This report highlights the challenges of patient care in resource limited settings. It would have been prudent to have the diagnosis made by a dermatologist and further confirmed by histopathology. In Uganda, there is only one consultant dermatologist and the process of having histopathology before treatment is long and complicated. In a situation where the hands of the clinician were tied as to do the best to relieve symptoms of a 
patient in the midst of the paucity of HAART, we had to start the patients on chloroquine. Due to the unavailability of free HAART at the time, we were unable to start our patients on definitive HIV treatment, despite all three patients having documented CD4 counts below 200cells/ml.

\section{CONCLUSION}

Our report suggests that chloroquine treatment may be beneficial in certain HIV seropositive patients with psoriasis. Although biologic-immune-response modifiers that specifically target key mechanisms of the pathogenesis of psoriasis have been shown to be effective [50-52], the costs of these drugs are prohibitively expensive for use in resource limited settings. Chloroquine on the other hand is cheap, easy to use and is a widely available drug. Based on our findings and those reported in the literature [17], a clinical trial to evaluate the effect of antimalarial therapy on psoriasis would be beneficial.

\section{ACKNOWLEDGEMENTS}

The authors wish to thank the patients who kindly accepted us to report about their illness and treatment. We also extend our gratitude to the nurses, counselors and physicians at the Infectious Diseases Institute who provided care to the patients in this report.

\section{REFERENCES}

[1] Greaves MW, Weinstein GD. Treatment of psoriasis. N Engl J Med $1995 ; 332: 581-8$

[2] Kurd SK, Gelfand JM. The prevalence of previously diagnosed and undiagnosed psoriasis in US adults: results from NHANES 20032004. J Am Acad Dermatol 2009; 60: 218-24.

[3] Gelfand JM, Stern RS, Nijsten T, et al. The prevalence of psoriasis in African Americans: results from a population-based study. J Am Acad Dermatol 2005; 52: 23-6.

[4] Leder RO, Farber EM. The variable incidence of psoriasis in subSaharan Africa. Int J Dermatol 1997; 36: 911-9.

[5] Duvic M, Johnson TM, Rapini RP, Freese T, Brewton G, Rios A. Acquired immunodeficiency syndrome-associated psoriasis and Reiter's syndrome. Arch Dermatol 1987; 123: 1622-32.

[6] Kaplan MH, Sadick NS, Wieder J, Farber BF, Neidt GW. Antipsoriatic effects of zidovudine in human immunodeficiency virus-associated psoriasis. J Am Acad Dermatol 1989; 20: 76-82.

[7] Njobvu P, McGill P. Psoriatic arthritis and human immunodeficiency virus infection in Zambia. J Rheumatol 2000; 27: 1699-702.

[8] Reveille JD, Conant MA, Duvic M. Human immunodeficiency virus-associated psoriasis, psoriatic arthritis, and Reiter's syndrome: a disease continuum? Arthritis Rheum 1990; 33: 1574-8.

[9] Johnson TM, Duvic M, Rapini RP, Rios A. AIDS exacerbates psoriasis. N Engl J Med 1985; 313: 1415.

[10] Arnett FC, Reveille JD, Duvic M. Psoriasis and psoriatic arthritis associated with human immunodeficiency virus infection. Rheum Dis Clin North Am 1991; 17: 59-78.

[11] Pallangyo KJ. Cutaneous findings associated with HIV disease including AIDS: experience from Sub Saharan Africa. Trop Doct 1992; 22(Suppl 1): 35-41, 60

[12] Wolfer LU, Djemadji-Oudjiel N, Hiletework M, et al. HIVassociated psoriasis: clinical and histological observations in 36 patients. Hautarzt 1998; 49: 197-202.

[13] Obuch ML, Maurer TA, Becker B, Berger TG. Psoriasis and human immunodeficiency virus infection. J Am Acad Dermatol 1992; 27(5 Pt 1): 667-73.

[14] No authors listed. Zidovudine improves psoriasis in HIV-positive males. Indian Med Trib $1994 ; 2: 11$.

[15] Duvic M, Crane MM, Conant M, Mahoney SE, Reveille JD, Lehrman SN. Zidovudine improves psoriasis in human immunodeficiency virus-positive males. Arch Dermatol 1994; 130: 447-51.

[16] Cornbleet T. Action of synthetic antimalarial drugs on psoriasis. $\mathrm{J}$ Invest Dermatol 1956; 26: 435-6.
[17] Herman SM, Shin MH, Holbrook A, Rosenthal D. The role of antimalarials in the exacerbation of psoriasis: a systematic review. Am J Clin Dermatol 2006; 7: 249-57.

[18] Sorbara S, Cozzani E, Rebora A, Parodi A. Hydroxychloroquine in psoriasis: is it really harmful? Acta Derm Venereol 2006; 86: 450-1.

[19] Sayers ME, Mazanec DJ. Use of antimalarial drugs for the treatment of psoriatic arthritis. Am J Med 1992; 93: 474-5.

[20] Kuflik EG. Effect of antimalarial drugs on psoriasis. Cutis 1980; 26: $153-5$.

[21] Jajic Z, Jajic I, Grazio S. Chloroquine in the treatment of psoriatic arthritis. Reumatizam 1995; 42: 7-9.

[22] Gladman DD, Blake R, Brubacher B, Farewell VT. Chloroquine therapy in psoriatic arthritis. J Rheumatol 1992; 19: 1724-6.

[23] Vine JE, Hymes SR, Warner NB, Cohen PR. Pustular psoriasis induced by hydroxychloroquine: a case report and review of the literature. J Dermatol 1996; 23: 357-61.

[24] Marguerie L, Flipo RM, Grardel B, Beaurain D, Duquesnoy B, Delcambre B. Use of disease-modifying antirheumatic drugs in patients with psoriatic arthritis. Joint Bone Spine 2002; 69: 275-81.

[25] Damstra RJ, van Vloten WA. Exacerbation of psoriasis caused by malaria prophylaxis with chloroquine and proguanil. Ned Tijdschr Geneeskd 1991; 135: 671-3.

[26] Nicolas JF, Mauduit G, Haond J, Chouvet B, Thivolet J. Severe psoriasis induced by chloroquine (nivaquine). Ann Dermatol Venereol 1988; 115: 289-93.

[27] Luzar MJ. Hydroxychloroquine in psoriatic arthropathy: exacerbations of psoriatic skin lesions. J Rheumatol 1982; 9: 462-4

[28] Baker $\mathrm{H}$. The influence of chloroquine and related drugs on psoriasis and keratoderma blenorrhagicum. Br J Dermatol 1966; 78: 161.

[29] Sperber K, Kalb TH, Stecher VJ, Banerjee R, Mayer L. Inhibition of human immunodeficiency virus type 1 replication by hydroxychloroquine in $\mathrm{T}$ cells and monocytes. AIDS Res Hum Retroviruses 1993; 9: 91-8.

[30] Tsai WP, Nara PL, Kung HF, Oroszlan S. Inhibition of human immunodeficiency virus infectivity by chloroquine. AIDS Res Hum Retroviruses 1990; 6: 481-9.

[31] Pardridge WM, Yang J, Diagne A. Chloroquine inhibits HIV-1 replication in human peripheral blood lymphocytes. Immunol Lett 1998; 64: 45-7.

[32] Savarino A, Gennero L, Chen HC, et al. Anti-HIV effects of chloroquine: mechanisms of inhibition and spectrum of activity. AIDS 2001; 15(17): 2221-9.

[33] Savarino A, Lucia MB, Rastrelli E, et al. Anti-HIV effects of chloroquine: inhibition of viral particle glycosylation and synergism with protease inhibitors. J Acquir Immune Defic Syndr 2004; 35: 223-32.

[34] Neely M, Kalyesubula I, Bagenda D, Myers C, Olness K. Effect of chloroquine on human immunodeficiency virus (HIV) vertical transmission. Afr Health Sci 2003; 3: 61-7.

[35] Savarino A, Boelaert JR, Cassone A, Majori G, Cauda R. Effects of chloroquine on viral infections: an old drug against today's diseases? Lancet Infect Dis 2003; 3: 722-7.

[36] Joshi SR, Butala N, Patwardhan MR, Daver NG, Kelkar D. Low cost anti-retroviral options: chloroquine based ARV regimen combined with hydroxyurea and lamivudine: a new economical triple therapy. J Assoc Physicians India 2004; 52: 597-8.

[37] Paton NI, Aboulhab J, Karim F. Hydroxychloroquine, hydroxycarbamide, and didanosine as economic treatment for HIV-1. Lancet 2002; 359: 1667-8

[38] Paton NI, Aboulhab J. Hydroxychloroquine, hydroxyurea and didanosine as initial therapy for HIV-infected patients with low viral load: safety, efficacy and resistance profile after 144 weeks. HIV Med 2005; 6: 13-20.

[39] Wolf R, Schiavo AL, Lombardi ML, de Angelis F, Ruocco V. The in vitro effect of hydroxychloroquine on skin morphology in psoriasis. Int J Dermatol 1999; 38: 154-7.

[40] Schopf RE, Ockenfels HM, Schultewolter T, Morsches B. Chloroquine stimulates the mitogen-driven lymphocyte proliferation in patients with psoriasis. Dermatology 1993; 187: 100-3.

[41] Tsankov N, Angelova I, Kazandjieva J. Drug-induced psoriasis. Recognition and management. Am J Clin Dermatol 2000; 1: 15965 .

[42] Khosravi AR, Mansouri P, Moazzeni M. Case report: chronic dermatophyte infection in a patient with vitiligo and discoid lupus erythematosus. Mycoses 2000; 43: 317-9. 
[43] Newman SL, Gootee L, Brunner G, Deepe GS, Jr. Chloroquine induces human macrophage killing of Histoplasma capsulatum by limiting the availability of intracellular iron and is therapeutic in a murine model of histoplasmosis. J Clin Invest 1994; 93: 1422-9.

[44] Dias-Melicio LA, Moreira AP, Calvi SA, Soares AM. Chloroquine inhibits Paracoccidioides brasiliensis survival within human monocytes by limiting the availability of intracellular iron. Microbiol Immunol 2006; 50: 307-14.

[45] Levitz SM, Harrison TS, Tabuni A, Liu X. Chloroquine induces human mononuclear phagocytes to inhibit and kill Cryptococcus neoformans by a mechanism independent of iron deprivation. J Clin Invest 1997; 100: 1640-6.

[46] Byrd TF, Horwitz MA. Chloroquine inhibits the intracellular multiplication of Legionella pneumophila by limiting the availability of iron: a potential new mechanism for the therapeutic effect of chloroquine against intracellular pathogens. J Clin Invest 1991; 88: 351-7.

[47] Weber SM, Levitz SM, Harrison TS. Chloroquine and the fungal phagosome. Curr Opin Microbiol 2000; 3: 349-53.

[48] Krogstad DJ, Schlesinger PH. Acid-vesicle function, intracellular pathogens, and the action of chloroquine against Plasmodium falciparum. N Engl J Med 1987; 317: 542-9.

[49] Naldi L, Gambini D. The clinical spectrum of psoriasis. Clin Dermatol 2007; 25: 510-8.

[50] Schon MP, Boehncke WH. Psoriasis. N Engl J Med 2005; 352: 1899-912.

[51] Langley RG, Gupta AK, Cherman AM, Inniss KA. Biologic therapeutics in the treatment of psoriasis.. J Cutan Med Surg 2007; 11: 99-122.

[52] Lebwohl MG. Advances in psoriasis. Arch Dermatol 2005; 141: 1589-90.

Received: March 20, 2009

(C) Shihab et al:; Licensee Bentham Open.

This is an open access article licensed under the terms of the Creative Commons Attribution Non-Commercial License (http://creativecommons.org/licenses/by$\mathrm{nc} / 3.0 /$ ) which permits unrestricted, non-commercial use, distribution and reproduction in any medium, provided the work is properly cited. 